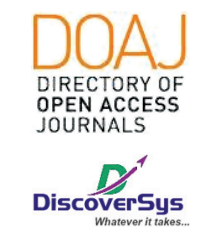

Published by DiscoverSys

\section{The effect of castration towards the microstructure of Hippocampus in Wistar rats}

\author{
Presanavathy P. Tharmalingam, ${ }^{1 *}$ Nyoman Mangku Karmaya, ${ }^{2}$ \\ I Nyoman Gede Wardana²
}

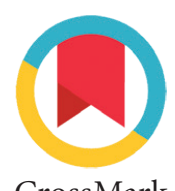

CrossMark

\section{ABSTRACT}

Background: Male ageing is mostly referred to as the declining of the capacity of a man due to age. Even though the physical changes cause by ageing are noticeable, there are several effects of ageing in a male that are concealed by the physical appearance, such as a lower level of testosterone. This study aims to determine the effect of lower testosterone towards the neuron, neuroglia and vasculature of Hippocampus.

Methods: An analytic observational study with two-group posttestonly randomized experiment with treatment was conducted among 10 Wistar rats (Rattus norvegicus). Variables assessed in this study were the number of neurons, neuroglia and vasculature of Hippocampus. Data were analyzed using SPSS version 17 for Windows.

Results: The average number of neuron cells of Hippocampus was significantly lower in the treatment group compared with control $(p=$ 0.007). The significantly lower in the number of neuroglia and vasculature of Hippocampus was also found in the treatment group compared with the control group ( $p=0.014$ and 0.004 , respectively) following castration.

Conclusion: Hence, we can conclude that the castration has a significant effect in lowering the level of testosterone, number of neurons, neuroglia and vasculature in the Hippocampus of Wistar rats.
'Undergraduate Student, Faculty of Medicine, Universitas Udayana, Bali, Indonesia

${ }^{2}$ Department of Anatomy, Faculty of Medicine, Universitas Udayana, Bali, Indonesia
${ }^{*}$ Correspondence to: Presanavathy P. Tharmalingam, Undergraduate Student, Faculty of Medicine, Universitas Udayana, Bali, Indonesia

presanalingam@gmail.com

Received: 2019-09-01 Accepted: 2020-05-20 Published: 2020-08-01

Key Words: Testosterone, Hippocampus, Neurons, Neuroglia, Vasculature.

Cite This Article: Tharmalingam,P.P., Karmaya, N.M., Wardana, I.N.G. 2020. The effect of castration towards the microstructure of Hippocampus in Wistar rats. Intisari Sains Medis 11(2): 597-600. D0I: 10.15562/ism.v11i2.601

\section{INTRODUCTION}

Male ageing mostly refers to the declining of the capacity of a man due to age. ${ }^{1}$ Even though the physical changes cause by ageing are noticeable, there are several effects of ageing in a male that are concealed by the physical appearance such as a lower level of testosterone. ${ }^{2}$

Testosterone is a male steroid hormone that plays a significant role in the reproductive system of a male to make sure the male can be sexually stimulated. ${ }^{3}$ The production of testosterone takes place in the testes of a male. ${ }^{3}$ The production first starts in the hypothalamus sends a message to the pituitary gland, and from there the instruction given to the testes about the amount of testosterone should be produced. ${ }^{4}$

Lowered level of testosterone in a male causes effects to a male in various ways. Apart from being sexually dysfunction, a male is capable of developing other symptoms as the consequences of a lower level of testosterone. ${ }^{5}$ For instance, a male with a low level of testosterone will be having mood problems or might be in depression. ${ }^{6}$ Besides, a lower level of testosterone also causes the libido and muscle mass of the male to decrease as well. ${ }^{5,6}$

Hippocampus of human brain functions in storing memories and aid in thinking and learning skills. ${ }^{7,8}$ The organ located in the medial temporal lobe of the brain is where the neurogenesis takes place. ${ }^{7}$ This regenerates new cells every time and inter-connects with each other to interpret and store memories. ${ }^{9}$ Both the spatial and long term memories will be saved as the cells generate and functions normally. ${ }^{9}$

Based on those mentioned above, this study aims to determine the effect of castration towards the microstructure of Hippocampus in Wistar rats through the evaluation of the number of neurons, neuroglia, and vasculature.

\section{METHODS}

This is analytic observation research with two-group posttest-only randomized experiment with treatment which conducted among 10 Wistar rats. This research will be carried out at the Animal Laboratory of Faculty of Medicine, Udayana University with several preparations will be done at distinctive places. This research takes about two months to be completed, which is from April 2019 to June 2019. The population target for this study is male rat species of Rattus Norvegicus age four months old. All the rats selected are to be in a good health condition. The selection of the rats is made randomly through the method of simple random allocation. The ten rats are then divided 
into two groups, with five rats in each of the groups, respectively. The rats in the control group (P0) were kept natural. Whereas, the treatment group (P1) were castrated to reduce the level of testosterone in the male rats. Both the rats in the control and treatment group were kept for 30 days before dissected and remove the brain to observe the changes that take place in the microstructure of the Hippocampus of the brain.

The use and dispose of these animal samples were followed according to the procedure of the Ethical Commission at the end of the research. The samples that have been used will be disposed of appropriately in a plastic bag and will be buried. Independent variable of this research is castration done to the male rats to lower the testosterone level. Whereas, the dependent variable is the number of neurons, neuroglia and vasculature in the Hippocampus of the brain. The controlled variables in this research are the age, gender, food and environment of the samples.

Analysis of research data to calculate the mean and standard deviation of the number of neurons, neuroglia and vasculature of Hippocampus. Normality analysis data of the number of neurons, neuroglia and vasculature by the test of Shapiro Wilk, with the sense of significance $a=0.05$, obtained result $\mathrm{p}>0.05$ which means data in all groups were normally distributed so that it continued with parametric tests. Analysis of variance homogeneity data of the number of neurons, neuroglia and vasculature by using Levene test, variance result obtained homogeny as the value of $\mathrm{p}>0.05$. Data were analyzed using SPSS version 17 for Windows to determine the significant difference between two groups in the number of neurons, neuroglia and vasculature.

\section{RESULTS}

Normality test was carried out by using the Shapiro Wilk test because the sample of subjects was small in less than 50 subjects. The results of the analysis show that the data were normally distributed ( $p$ > 0.05 ), and the data variance was also homogeneous $(\mathrm{p}>0.05)$ (Table 1).

Data analysis with an Independent T-Test have been done to determine the mean difference in the number of neurons, neuroglia and vasculature between groups. The Independent T-Test results were described in Table 2, and Figure 1 show a data descriptive regarding the number of neuron, neuroglia and vasculature between groups.

The test showed that the mean number of neurons between groups was significantly different $(p=0.007)$. Also, the mean number of neuroglia between groups was significantly different $(\mathrm{p}=0.014)$. Besides, the test showed that the mean number of vasculature between groups was significantly different $(p=0.004)$ (Table 2$)$. The image of differences in the hippocampus cell in the control and treatment groups can be seen in Figure 2.

Table 1 Normality test by Shapiro Wilk

\begin{tabular}{llccc}
\hline \multirow{2}{*}{ Variable } & & \multicolumn{3}{c}{ Shapiro-Wilk } \\
\cline { 3 - 5 } Number of Neurons & Group & Statistic & Df & Sig. \\
& Control & 0.943 & 5 & 0.688 \\
\multirow{3}{*}{ Number of Neuroglia } & Treatment & 0.940 & 5 & 0.665 \\
& Control & 0.935 & 5 & 0.631 \\
Number of Vasculatures & Treatment & 0.874 & 5 & 0.282 \\
& Control & 0.887 & 5 & 0.342 \\
& Treatment & 0.882 & 5 & 0.318 \\
\hline
\end{tabular}

Table 2 Independent t-test to the number of neuron, neuroglia and vasculature between groups

\begin{tabular}{lcccc}
\hline Variables & Group & Mean Difference & SE Difference & $\mathbf{p}$ \\
\hline Number of Neurons & P0 & 33.664 & 9.326 & 0.007 \\
Number of Neuroglia & P1 & & & 0.014 \\
Number of Vasculatures & P0 & 22.466 & 7.123 & 0.004 \\
& P1 & & 5.768 & \\
\hline
\end{tabular}

$\mathrm{P} 0=$ Control; P1=Treatment; SE: Standard Error; P-value was considered significant if less than 0.05 


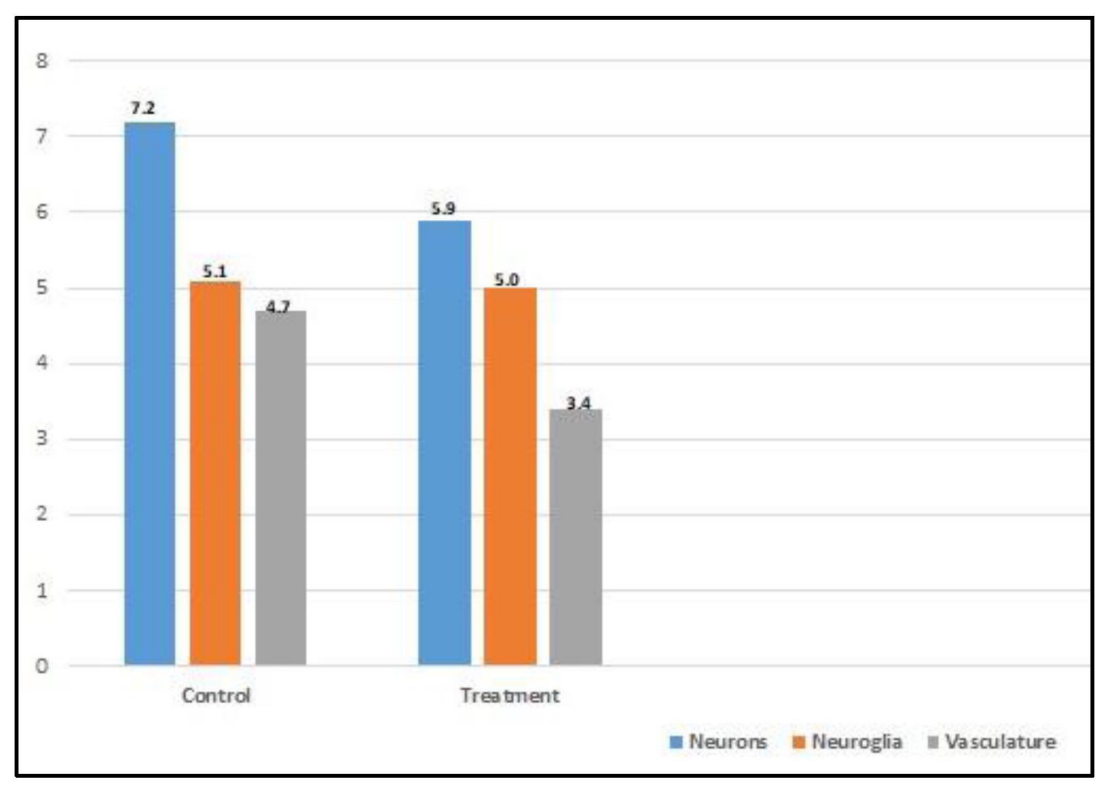

Figure 1 The number of neurons, neuroglia and vasculature between groups
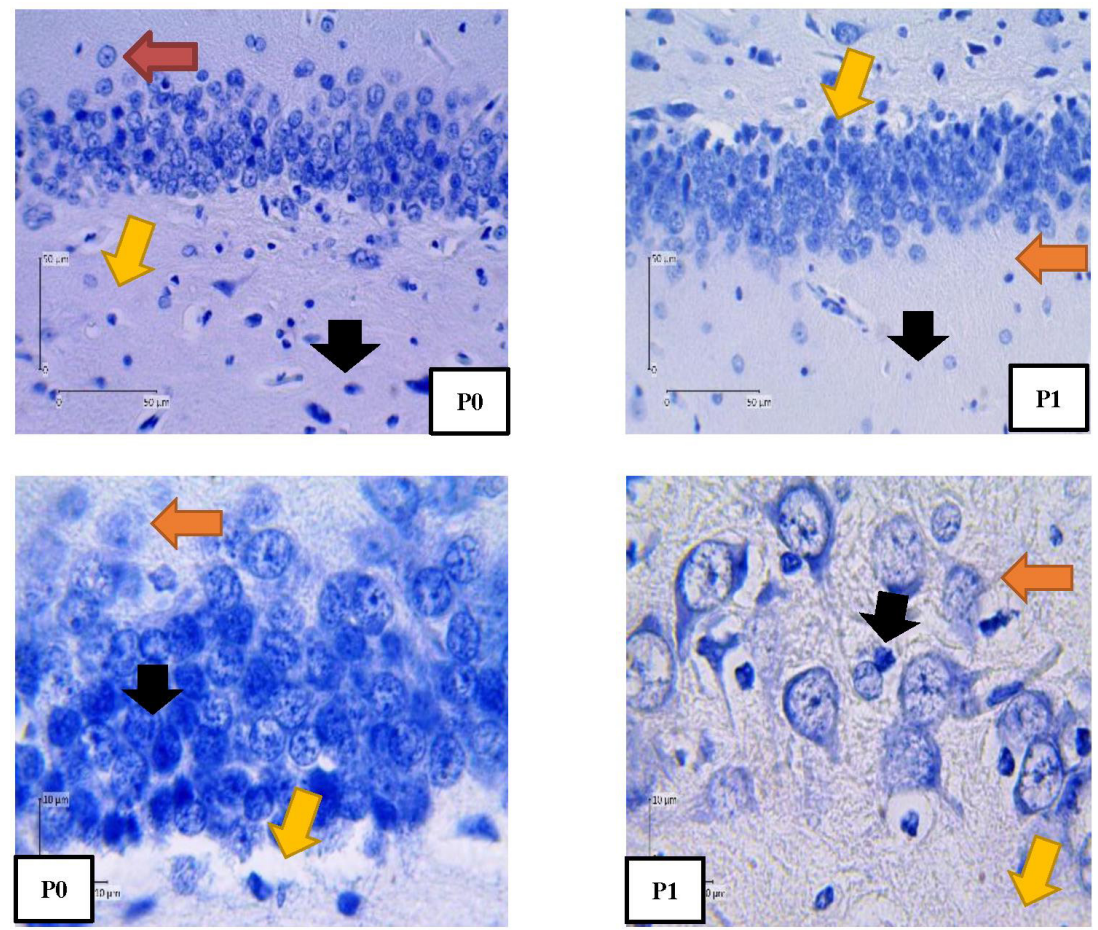

Figure 2 Image of hippocampus cell with 400x magnification of control group (P0) and treatment group (P1) (Above); Image of hippocampus cell 1000x magnification of control group (P0) and treatment group (P1) (Below) (Black Arrow: Neurons; Red Arrow: Neuroglia; Yellow Arrow: Vasculature)

\section{DISCUSSION}

Circulating androgens are converted to metabolites that have a wide range of biological activities, in different regions of the brain. ${ }^{10}$ This extensive metabolism provides mechanisms for both control, in terms of regulating the cellular responses that can be obtained via modulation of the activity of the relevant rate-limiting enzymes, as well as for diversification of the cellular effects of the circulating hormones. ${ }^{11}$

Testosterone is made into estradiol in few areas of the brain, including the Hippocampus. ${ }^{12}$ It is also being used, in both neurons and glia, to convert to the potent androgen, dihydrotestosterone (DHT). ${ }^{12,13}$ Called as aromatase, the enzyme that converts testosterone to estrogen was produced in the brain's Hippocampus and cerebral cortex in a variety of species that includes humans. ${ }^{13}$

Aromatase in Hippocampus serve as a medium in making long-term memories and spatial memory, and the cerebral cortex. ${ }^{14}$ This happens as the synaptic connection takes place in the Hippocampus with the presence of aromatase. ${ }^{14}$ The interconnection between the neurons aids in the process of interpreting information which is essential to memory, attention, awareness and thought. Removing out aromatase also reduces expression of CREB, a major transcription factor known to play a primary role in learning and memory, as well as a neuronnourishing brain-derived neurotrophic factor. ${ }^{15}$

The result of androgens affecting the Hippocampus includes a difference in neurogenesis in the subgranular zone of the dentate gyrus. ${ }^{16}$ The changes cause by androgens on the hippocampal structure are the difference in glia, in particular astrocytes. ${ }^{16}$ These effects are important not only because of the role of glia in neurosteroid biosynthesis but also because glia mediate some of the neuronal effects of steroid hormone action. ${ }^{17}$

Result of this research shows that the rats which were castrated had its testosterone level to be decreased. This eventually reduces the microstructure of the Hippocampus, which are the neuron, neuroglia and vasculature. The result of this research shows the number of neurons, neuroglia and vasculature in the treatment group are lower compared to the control group. A previous study has been noticed that low testosterone level will affect the adult neurogenesis through several pathways. ${ }^{18}$

\section{CONCLUSION}

Based on the present research that has been conducted, we conclude that the number of neurons, neuroglia, and vasculature in the Hippocampus of castrated rats is lower compared to the number of neuron in the Hippocampus of non-castrated rats.

\section{CONFLICT OF INTEREST}

There is no competing interest regarding the manuscript. 


\section{ETHICS CONSIDERATION}

This research has been approved by the Ethical Commission of Faculty of Medicine, Universitas Udayana, Bali, Indonesia.

\section{FUNDING}

None.

\section{AUTHOR CONTRIBUTION}

All of the authors are equally contributed to the study from the conceptual framework, data gathering, data analysis, until reporting the results of study through publication.

\section{REFERENCES}

1. Lunenfeld B. The ageing male: demographics and challenges. World J Urol. 2002;20(1):11-16.

2. McBride JA, Carson CC 3rd, Coward RM. Testosterone deficiency in the aging male. Ther Adv Urol. 2016;8(1):47-60.

3. Rastrelli G, Corona G, Maggi M. Testosterone and sexual function in men. Maturitas. 2018;112:46-52.

4. Bain J. The many faces of testosterone. Clin Interv Aging. 2007;2(4):567.

5. Tyagi V, Scordo M, Yoon RS, Liporace FA, Greene LW. Revisiting the role of testosterone: Are we missing something?. Rev Urol. 2017;19(1):16-24

6. Morgentaler A. The testosterone Trials: What the results Mean for Health Care Providers and for Science. Current Sexual Health Reports.2017;9(4):290-295.

7. Voss JL, Bridge DJ, Cohen NJ, Walker JA. A Closer Look at the Hippocampus and Memory. Trends Cogn Sci. 2017;21(8):577-588.

8. Wirata G, Santoso P, Dewantari P. Microstructural aspect of pineal body: pinealocytes population. Intisari Sains Medis. 2018;9(1):25-30.
9. Sapiurka M, Squire LR, Clark RE. Distinct roles of hippocampus and medial prefrontal cortex in spatial and nonspatial memory. Hippocampus. 2016;26(12):1515-1524.

10. Cooke BM, Tabibnia G, Breedlove SM. A brain sexual dimorphism controlled by adult circulating androgens. Proc Natl Acad Sci U S A. 1999;96(13):7538-7540.

11. Zirkin BR, Papadopoulos V. Leydig cells: formation, function, and regulation. Biol Reprod. 2018;99(1):101-111.

12. Konkle AT, McCarthy MM. Developmental time course of estradiol, testosterone, and dihydrotestosterone levels in discrete regions of male and female rat brain. Endocrinology. 2011;152(1):223-235.

13. Tautvydaite D, Manuel AL, Nahum L, Adam-Darqué A, Ptak R, Schnider A. Absence of an early hippocampal encoding signal after medial temporal lesions: No consequence for the spacing effect. Hippocampus. 2019;29(7):587-594.

14. Rosenfeld CS, Shay DA, Vieira-Potter VJ. Cognitive Effects of Aromatase and Possible Role in Memory Disorders. Front Endocrinol (Lausanne). 2018;9:610.

15. Ortega-Martínez S. A new perspective on the role of the CREB family of transcription factors in memory consolidation via adult hippocampal neurogenesis. Front Mol Neurosci. 2015;8:46. Published 2015 Aug 26. doi:10.3389/ fnmol.2015.00046

16. Duarte-Guterman P, Lieblich SE, Wainwright SR, Chow C, Chaiton JA, Watson NV, et al. Androgens Enhance Adult Hippocampal Neurogenesis in Males but Not Females in an Age-Dependent Manner. Endocrinology. 2019;160(9):2128-2136.

17. Atwi S, McMahon D, Scharfman H, MacLusky NJ. Androgen Modulation of Hippocampal Structure and Function. Neuroscientist. 2016;22(1):46-60.

18. Spritzer MD, Roy EA. Testosterone and Adult Neurogenesis. Biomolecules. 2020;10(2):225.

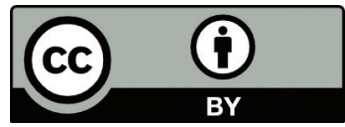

This work is licensed under a Creative Commons Attribution 